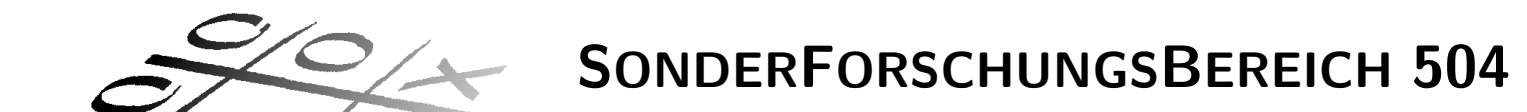

Rationalitätskonzepte,

Entscheidungsverhalten und

ökonomische Modellierung

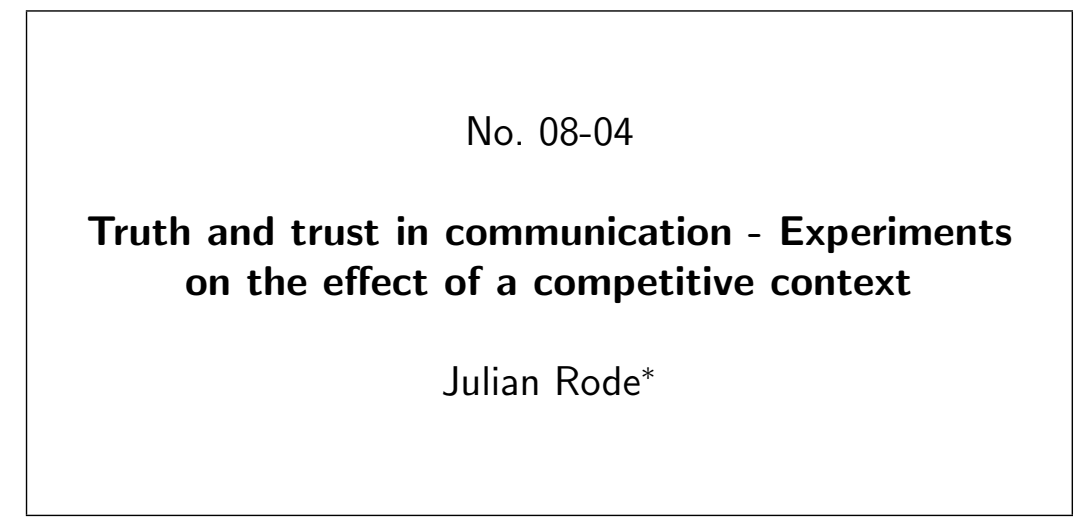

April 2008

Financial support from the Deutsche Forschungsgemeinschaft, SFB 504, at the University of Mannheim, is gratefully acknowledged.

*Sonderforschungsbereich 504, email: jrode@sfb504.uni-mannheim.de

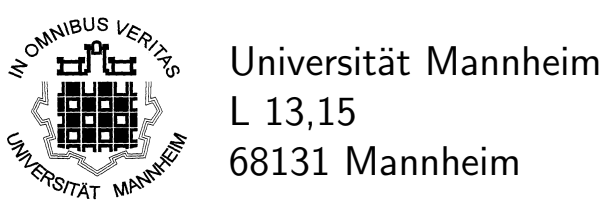




\title{
Truth and trust in communication Experiments on the effect of a competitive context
}

\author{
Julian Rode*
}

February 2008

\begin{abstract}
The paper employs laboratory experimentation to study the effect of competition on truth telling and trust in communication. A sequence of either competitive or cooperative interactions preceded an experimental communication game. In the game, informed advisors sent a recommendation to decision-makers who faced uncertainty about the consequences of their choice. While many advisors told the truth against their monetary self-interest, the propensity to tell the truth was unaffected by the contextual priming. In contrast, decision-makers trusted significantly less in a competitive context. The effect was strongest when they faced full uncertainty. The paper relates this result to psychological and neuro-economic findings on automatic information processing. The data of this study were largely in line with Subjective Equilibrium Analysis (Kalai and Lehrer, 1995).
\end{abstract}

Keywords: experimental economics, truth telling, trust, asymmetric information, context effects, competition, automatic information processing; subjective beliefs

J.E.L. Classification: D01; D8; Z13

\footnotetext{
* Postal address: Universität Mannheim, SFB 504, L 13, 15, 68131 Mannheim, Germany; email: jrode@sfb504.uni-mannheim.de; Tel.: 0049-6211813434; Fax 0049-6211813451.

I am especially indebted to Marc Le Menestrel and Robin Hogarth. Rosemarie Nagel and Uri Gneezy gave very helpful advice. I also thank Michael Bashshur, Christiane Schwieren, Karl Schlag, Gary Charness, Daniel Schunk, Fabrizio Germano, participants of the MERSS summer school 2005 in Mannheim, participants of the Ratio colloquium 2006 in Stockholm, and two anonymous referees for useful comments. Thanks also to Enric Sonria and Eva Benz for help with the experiments, and Alfonso Ugarte and Aniol Llorente for classifying participants' explanations.
} 


\section{Introduction}

It has been shown that trust in institutions and in fellow citizens is related to the smooth functioning of societies and to their economic development (Knack and Keefer, 1997). Trust promotes cooperation, especially in large organizations, including firms (La Porta et al., 1997) ${ }^{1}$. In his work on trust and prosperity, Fukuyama (1995) provides a very general definition of trust as "the expectation that arises within a community of regular, honest, and cooperative behavior, based on commonly shared norms, on part of other members of that community (p. 26)”. In the present study, the focus is on trust with respect to honesty in communication, i.e., telling the truth. Telling the truth is a particularly important norm, which is shared by communities around the globe. Trust with respect to truth telling is also what Rotter $(1971,1980)$ emphasizes when he defines trust as a "generalized expectancy held by an individual that the word, promise, oral or written statement of another individual or group can be relied on."”2

Both truth telling and trust - as specified here - play a role in situations of information asymmetry in which people can rely on a report or on advice from a better informed person. These situations have received great attention in the economic literature, which is by no means surprising if one considers their ubiquity in social and economic life, e.g. any sales situation where an expert has superior knowledge (cf., Akerlof, 1970). Most theoretical work relies on the economic rationality paradigm, which assumes that people lie whenever they have an incentive to do so. According to such analysis, “cheap talk” conveys informational content only in a limited number of settings in which both parties know that incentives are aligned (Farrell and Rabin, 1996; Crawford, 1998). Yet, it is questionable whether that kind of confidence should be called trust at all, or whether trust should rely on a belief in truth telling independently of the incentive structure (see Knack, 2001; Rotter, 1980; Yamagishi and Yamagishi, 1994). Moreover, experimental testing of the theoretical predictions have frequently reported "overcommunication”, i.e., more truth telling than economic equilibrium theory would predict (e.g., Blume et al., 2001; Cai and Wang, 2006). Recently, Gneezy`s (2005) contribution on the

\footnotetext{
${ }^{1}$ These studies on "social capital" use survey data to measure the level of trust, more specifically the question "Generally speaking, would you say that most people can be trusted, or that you can't be too careful in dealing with people?”

${ }^{2}$ The notion of trust both in everyday usage and in the interdisciplinary literature is broad (McKnight and Chervany, 2001). Much experimental work in economics employs a "Trust Game” by Berg et al. (1995) which tests whether and to what extent participants' reveal trust that a counterpart will reciprocate and return a fair share of money.
} 
role of consequences for lying has started a discussion about the motivations behind truth telling (Charness and Dufwenberg, 2005; Sutter, 2006; Hurkens and Kartik, 2006).

The present experimental study employed a two-player communication game with asymmetric information to study truth telling and trust in a controlled laboratory setting. The main purpose of the experiments was to investigate the sensitivity of truth-telling and trust to the surrounding context - in particular to a competitive vs. a cooperative environment. The role of context for decision-making is increasingly recognized in the economic literature (Levitt and List, 2006). For instance, Cooper et al. (1999) and Liberman et al. (2004) show that contextual framing in the instructions can significantly alter behavior in experimental games. With regard to competition, several authors have investigated to what extent it may potentially change human behavior. Ross and Robertson (2000) find in a survey study that people's inclination to deceive others changes depending on the role of the counterpart, e.g. the own firm, a client, or a competitor. Hegarty and Sims (1978) find in a laboratory experiment that increased competition results in more unethical behavior when this serves to enhance own profits. Ford and Richardson (1994) point out that specifics of the reward systems and competitiveness of the organizational structure are contextual variables that may influence how ethical decisions are made. Brandts et al. (2004) demonstrate experimentally that competition has a negative effect on the emotional disposition towards others.

Participants in the present experiments interacted in a series of tasks before they played a communication game. The tasks served to induce either a cooperative or a competitive environment. In the communication game, participants in the role of decision makers had to make a choice between several options which had unknown consequences for themselves and for informed advisors. In particular, decision makers had no information about the payoff alignment when they received a recommendation from an advisor. Moreover, contextual effects were tested in two experiments in which decision makers faced either full uncertainty (Experiment 1 ) or partial uncertainty (Experiment 2).

While many advisors told the truth against their monetary interests, results from both experiments revealed no effect of the context on advisors' propensity to lie. However, decision makers trusted less when they were in a competitive context. This impact on trust was strongest when decision makers 
encountered full uncertainty about the consequences of their decisions. The latter finding stimulated conjectures about the prominence of automatic information processing as a psychological explanation of context effects (cf., Bargh and Chartrand, 1999, Sanfey et al., 2006).

From a practical perspective, the results naturally relate to work environments where competition can be induced, e.g., through a ranking-based reward scheme. If increased competition can have a detrimental effect on trust in communication, then it may undermine overall efficiency on a dimension that is difficult to observe and to measure. Conversely, inducing cooperation may have a positive effect.

The experimental data were characterized by large individual heterogeneity. For the partial uncertainty version of the communication game, the paper provides supplementary data on beliefs and verbal explanations. There was a strong relation between actions and beliefs about the counterpart's behavior. The paper therefore suggests a modeling framework based on subjective beliefs. Indeed, predictions from Subjective Equilibrium Analysis (Kalai and Lehrer, 1995) were in line with a large fraction of the data.

The paper is organized as follows. Section 2 motivates and specifies the experimental design. Section 3 presents the results of behavior in the communication game and of the supplementary data from Experiment 2. Section 4 discusses the main insights gained from this study, focusing on the effect of context on trust and on implications for theory. Section 5 concludes.

\section{Experimental design}

The experiments were computerized with z-tree software (Fischbacher, 1999) and they were conducted in the experimental laboratory (LEEX) at Pompeu Fabra University. Participants were 344 students from various fields of study. They were recruited using the ORSEE online recruitment system (Greiner, 2004) and earned on average $€$ 8.14. Sessions were conducted with 8 to 18 participants and lasted around sixty minutes - this included completing the post-experimental questionnaire. At the beginning of the experiment, participants were randomly assigned to computers; basic instructions were distributed and also read out aloud. Detailed instructions for the different parts of the experiment were shown on the computer screen (for further details, see Appendix). The analysis focuses on 
behavior in the communication game. However, the communication game was embedded into a series of tasks for which a cooperative and a competitive treatment were distinguished.

\section{The communication game}

Communication games represent situations in which communication links the superior information of an advisor with the action of a decision-maker (Crawford and Sobel, 1982). The present versions were inspired by Gneezy (2005).

Decision-makers had to make a choice between several options with consequences for the two players. They had none (Experiment 1) or very limited knowledge (Experiment 2) about the consequences of the options. Advisors had full information about the consequences and both participants knew this. Advisors were asked to send the message

"With option [ i ] you earn more money than with the other options."

where i specified one of the available options. Decision makers received the message and subsequently made their choice.

The payoff structure was non-aligned. The single truthful message recommended an option which did not lead to the highest payoff for the advisor (see payoff tables below). This may have given advisors an incentive to lie in the message. Importantly, decision-makers in both versions of the experiment had no information about the payoff alignment.

Additional options were added to Gneezy's two-option design. Sutter (2006) demonstrates that with two options and a non-aligned payoff structure, a considerable fraction of advisors send the truthful message and expect the decision maker to deviate from the advice. These advisors tell the truth as a strategic choice for their own benefit. In the design here, additional options served to rule out strategic considerations for truth-telling. Advisors had no incentive to send the truthful message if they wanted to maximize monetary self-interest and expected the decision maker to deviate.

Experiment 1 - "full uncertainty". There were six options. Only the advisor knew that the options gave the following gains:

option A: $\quad € \mathbf{1}$ to the advisor $\quad € 2$ to the decision maker

option B: $\quad € \mathbf{0}$ to the advisor $\quad € \mathbf{1}$ to the decision maker 


$\begin{array}{lll}\text { option C: } & € \mathbf{3} \text { to the advisor } & € \mathbf{2} \text { to the decision maker } \\ \text { option D: } & € \mathbf{1} \text { to the advisor } & € \mathbf{0} \text { to the decision maker } \\ \text { option E: } & € \mathbf{2} \text { to the advisor } & € \mathbf{3} \text { to the decision maker } \\ \text { option F: } & \boldsymbol{€} \mathbf{2} \text { to the advisor } & € \mathbf{1} \text { to the decision maker }\end{array}$

Obviously, advisors could infer that option E was the truthful message, while option C would give them the highest gain. Decision makers had no information apart from the message.

Experiment 2 - "partial uncertainty". There were three options. Decision makers were told that one option would lead to a gain of $€ 5$ for them, another one to $€ 3$, and a third to $€ 1$. They did not know which of the three options brought about which of the gains and they did not know the consequences for the advisor. Advisors knew that the options gave the following gains:
option A:
$€ \mathbf{1}$ to the advisor
$€ \mathbf{1}$ to the decision maker
option B:
$€ \mathbf{4}$ to the advisor
$€ \mathbf{3}$ to the decision maker
option C:
$€ \mathbf{3}$ to the advisor
$€ \mathbf{5}$ to the decision maker. ${ }^{3}$

Note that, in contrast to the full uncertainty condition, decision makers could infer from the additional information structure that that there was only one truthful message. Also, the numerical information $(1,3$, or 5) potentially allowed expected value calculations based on the belief whether the advisor would lie or tell the truth. However, the information did not reveal the (negative) payoff alignment.

\section{Experimental procedure}

The experimental procedure is illustrated in Table 1. The experiment consisted of six independent parts (participants were told in advance only that it consisted of "various" parts). In parts 1, 2, 4, and 5, participants performed different sets of exercises and were rewarded for their performance. In part 3, they interacted in a simultaneous move game with two-by-two symmetric actions. In part 6, participants played the communication game. In order to assure that behavior in the communication

\footnotetext{
${ }^{3}$ In Experiment 2 the decision maker could lose more $(€ 2)$ than the advisor could gain ( $\left.€ 1\right)$. This change compared to Experiment 1 was supposed to assure a significant fraction of truth-telling, so that changes in this fraction across treatments would become more apparent.
} 
game would not be influenced by reputation effects, participants were randomly (re)matched for each part to build teams of two. They were informed about their personal gain and the accumulated gain after each part.

In experiment 2 supplementary data were elicited. Beliefs about the counterpart's behavior were elicited from both advisors and decision makers. Expectations about the incentive alignment were elicited only from decision makers since advisors already knew that it was negative. In addition, all participants had to explain how they made their decision in the communication game. Finally, participants were paid their experimental gains.

Table 1 -- Summary of the experimental procedure

\section{Basic instructions}

Exercise 1

participants had 3 minutes to solve 30 simple calculations

(e.g., $8-4+19=[$ ] )

Exercise 2

participants had 3 minutes to answer 15 general knowledge questions

\section{Coordination game (in COOP) / Matching pennies game (in COMP)}

Exercise 3

participants had 3 minutes to estimate the distances between 8 pairs of cities (e.g., Paris - Rome [ ] )

Exercise 4

participants had 4 minutes to complete 17 sequences of numbers (e.g., $\left.6 \begin{array}{lllll}6 & 7 & 9 & 12 & {[}\end{array}\right]$ )

\section{Communication game}

[In Experiment 2: Belief elicitations]

\section{Post-questionnaire}




\section{Contextual variation: Cooperative vs. competitive treatment}

Participants performed several exercises (parts 1, 2, 4, and 5) and an additional game (part 3) to create a contextual setting. The following variation in the context served to distinguish the cooperative (COOP) from the competitive treatment (COMP):

Reward-structure in the exercises. The individual performance of both team members was rewarded in a piece-rate fashion and was summed to determine the total team gain. In COOP this total gain was split in equal parts between the two team-members. In COMP, the best performer received two thirds of the total gain, while the other received the remaining third. Hence, participants in both treatments had the incentive to perform as well as possible in each exercise. COMP, however, added competition, defined as a situation in which the goals of the two parties are negatively linked (cf., van Knippenberg et al., 2001; Schwieren et al., 2006). It became profitable to outperform the other team member. ${ }^{4}$

Wording and information. In the exercises (parts 1, 2, 4, and 5) in COMP, participants were explicitly told that they "compete” against the other participant, and they were informed whether they had "won" or "lost" against the other. None of this was said in COOP. (See Appendix for the instructions of the first exercise.)

Game in part 3. In this game, both team members had to choose simultaneously between "square" and "circle". In COOP, both were paid $€ 2$ if they made the same choice and nothing if they chose differently (i.e., positive aligned objectives in a “coordination game” structure). In COMP, one player gained $€ 2$ if both had chosen the same, the other gained if both have chosen differently (i.e., negative aligned objectives in a "matching pennies game” structure).

Note that the present procedure differed from experiments which study the sensitivity of behavior to different verbal descriptions of a game. For instance, Liberman et al. (2004) find that when the Prisoners Dilemma is labeled as Wall Street Game participants cooperate less compared to a label as Community Game. They conjecture that the "name of the game" alters the participants' perception of what constitutes normative play. Cooper et al. (1999) show that managers are more sensitive than students to context in the verbal description of a management related "ratchet effect" experiment. The context seems to help managers detect the analogy between the experimental task and the natural

\footnotetext{
${ }^{4}$ In practical terms, these reward structures closely resemble team performance pay with or without rewarding the team members for their rank in individual contribution (see e.g. Lawler, 2000, ch.9).
} 
setting with which they have experience. While the present study also investigates the effect of context, it is again emphasized that no different labels or verbal descriptions were given in the description of the communication game. Instead, prior interaction (parts 1 to 5) entailed contextual cues as a secondary but persistent side aspect within a sequence of interactive encounters. The rationale for that procedure was the pursuit of a close experimental representation of how a competitive or cooperative environment may affects truth-telling and trust (see Hogarth, 2005 on representative design), for example in a work environment.

\section{Results}

\section{Experiment 1 - "full uncertainty"}

Advisor behavior. Across both treatments, the majority of 43 advisors recommended option $\mathrm{C}$ (67\%), which implied the highest gain for themselves. 14 advisors (22\%) recommended option E, i.e., they told the truth against their monetary interest. Message B was sent 4 times (6\%), message D 3 times (5\%). None of the advisors sent messages A or F.

Table 2 compares the relative frequencies of messages that were sent in COOP and in COMP. It shows that there was no significant treatment effect on advisors’ propensity to lie.

Decision maker behavior. Overall, 42 advisors (66\%) followed the advice, 22 (34\%) deviated from the advice in favor of a different option. The data show that decision makers tended to trust the recommendations; messages were not regarded as meaningless. ${ }^{5}$

In COOP, 27 (84\%) decision makers followed the advice, only 15 (47\%) did so in COMP (1-tailed Fisher Exact test: $\mathrm{p}<.01)$. Hence, the behavioral data revealed a significant treatment effect on decision maker's propensity to follow the advice.

\section{Experiment 2 - "partial uncertainty"}

Advisor behavior. Across both treatments, the majority of 65 (60\%) recommended option B which gave the highest gain to themselves. 32 advisors (30\%) sent the truthful message with option C, and 11 advisors (10\%) recommended option A. Hence, as in experiment 1, a significant share of advisors told the truth against their monetary interests. This result is in line with previous studies on communication

\footnotetext{
${ }^{5}$ This may not be surprising, and yet it contradicts a result from Bayesian Nash equilibrium analysis: In communication games there always exists a "babbling equilibrium" in which communication is meaningless and should be ignored (Farell and Rabin, 1996). In that case, the Principle of Insufficient Reasoning (Laplace, 1824) would suggest that decision makers choose options randomly, i.e. with equal probability of $1 / 6$.
} 
in situations under asymmetric information (cf., Blume et al, 2001, Gneezy, 2005, Cai and Wang, 2006). It is emphasized that the design does not allow to disentangle possible motivations for truthful reporting, especially to what extent altruism, efficiency considerations, or an aversion to the act of lying play a role. A recent experimental study by Hurkens and Kartik (2006) focuses on this issue.

Table 2 shows no treatment effect on advisor behavior, thus replicating the result from experiment 1. Possibly the propensity to tell the truth is insensitive to a competitive context, but instead reflects stable social preferences. Alternatively, the contextual variation in this experiment may have been too small to create an effect, i.e., behavior was dominated by the general context of a laboratory experiment.

Table 2 -- Relative frequencies of messages and choices in COOP vs. COMP

Advisors

$\underline{\text { Messages }}$
Decision makers

$\underline{\text { Choices }}$

\section{Experiment 1}

$\begin{array}{lcccccccc} & \underline{\mathrm{A}} & \underline{\mathrm{B}} & \underline{\mathrm{C}} & \underline{\mathrm{D}} & \underline{\mathrm{E}} & \underline{\mathrm{F}} & \underline{\text { follow }} & \underline{\text { deviate }} \\ \begin{array}{ccccc}\mathrm{COOP} \\ (\mathrm{N}=2 \times 32)\end{array} & --- & .06 & .69 & .06 & .19 & --- & .84 & .16 \\ \left.\frac{\mathrm{COMP}}{\mathrm{N}=2 \times 32}\right) & --- & .06 & .66 & .03 & .25 & --- & .47 & .53\end{array}$

\section{Experiment 2}

\begin{tabular}{llllll} 
& $\underline{\mathrm{A}}$ & $\underline{\mathrm{B}}$ & $\underline{\mathrm{C}}$ & $\underline{\text { follow }}$ & deviate \\
$\begin{array}{l}\mathrm{COOP} \\
(\mathrm{N}=2 \times 54)\end{array}$ & .11 & .59 & .30 & .81 & .19 \\
$\frac{\mathrm{COMP}}{(\mathrm{N}=2 \times 54)}$ & .09 & .61 & .30 & .69 & .31 \\
\hline
\end{tabular}

Decision maker behavior. Overall, 81 decision makers (75\%) followed the given advice (see Table 2). Again, decision makers tended to trust recommendations.

In COOP 44 (81\%) decision makers followed the advice, 37 (69\%) did so in COMP (1-tailed Fisher Exact test: $\mathrm{p}=.09$ ). The data suggest a mild effect of the context on decision maker behavior in this experiment. 
Advisor beliefs. Advisors stated how many out of the nine decision makers in the session they expected to follow the advice. ${ }^{6}$ They received $€ 0.50$ for a correct guess. Table 3 shows how advisor beliefs varied between 0 and 9 (mean 4.6, standard deviation 2.3). The table depicts separately the distributions of beliefs for advisors who sent messages A, B and C. Advisors who sent message A tended to have a low belief with a mean of 2.3, whereas those who sent message B tended to have a high belief with a mean of $5.0(\mathrm{t}=4.23, \mathrm{p}<.01)$. In contrast, there was no clear pattern for the relation between sending the truthful message $C$ and the belief about decision makers' behavior (mean 4.7).

On average, advisors underestimated decision makers' true propensity to follow the advice - the actually observed $75 \%$ following would coincide with a belief of 6.8 . This result is line with Camerer et al. (1989), who show that it is difficult for an informed party to neglect own information (i.e., the non-aligned payoff structure) when building expectations about how an uninformed party will behave.

The mean of beliefs was 4.3 in COMP and 4.9 in COOP, this difference is not statistically significant. (Mann-Whitney rank test: $\mathrm{p}=.17$ ).

Table 3 -- Distribution of advisor beliefs about how many out of nine decision makers would follow the advice.

\begin{tabular}{lccccccccccc}
\hline Belief & $\underline{0}$ & $\underline{1}$ & $\underline{2}$ & $\underline{3}$ & $\underline{4}$ & $\underline{5}$ & $\underline{6}$ & $\underline{7}$ & $\underline{8}$ & $\underline{9}$ & $\underline{\text { mean }}$ \\
message A & 2 & 1 & 4 & 2 & 1 & 0 & 1 & 0 & 0 & 0 & 2.3 \\
$\underline{\text { message B }}$ & 1 & 1 & 0 & 13 & 19 & 6 & 10 & 8 & 2 & 5 & 5.0 \\
$\underline{\text { message C }}$ & 2 & 1 & 3 & 6 & 4 & 3 & 3 & 5 & 3 & 2 & 4.7 \\
\hline
\end{tabular}

Decision maker beliefs. Decision makers stated how many out of the nine advisors in the session they expected to tell the truth. They received $€ 0.50$ for a correct guess. Table 4 shows how their beliefs varied between 0 and 9 (mean 5.3, standard deviation 2.8). The table presents separately the distribution for decision makers who followed the advice and for those who deviated. Those who followed the advice had an average belief of 6.7; those who deviated had an average belief of $2.7(\mathrm{t}=$ $6.8, \mathrm{p}<.01)$

\footnotetext{
${ }^{6}$ All sessions in experiment 2 were run with exactly 18 participants.
} 
The mean belief of 5.3 shows that on average decision makers overestimated the advisors' true propensity to tell the truth; the actually observed 30\% truth telling would coincide with a belief of 2.3 . This is not surprising since decision makers did not know that the payoff structure was in fact nonaligned. The analysis of verbal explanations below will show that many expected it to be aligned, in which case there was no incentive to lie.

In the COMP treatment the mean of beliefs was 4.7, whereas it was 5.9 in COOP (Mann-Whitney rank test: $\mathrm{p}=.02$ ). This significant difference supports the finding that the context had an effect on decision makers also in the "reduced uncertainty" condition of experiment 2.

Table 4 -- Distribution of decision maker beliefs about how many out of nine advisors had told the truth in the advice.

\begin{tabular}{llllllllllll}
\hline Belief & $\underline{0}$ & $\underline{1}$ & $\underline{2}$ & $\underline{3}$ & $\underline{4}$ & $\underline{5}$ & $\underline{6}$ & $\underline{7}$ & $\underline{8}$ & $\underline{9}$ & $\underline{\text { mean }}$ \\
follow & 3 & 0 & 1 & 9 & 3 & 17 & 5 & 17 & 6 & 20 & 6.7 \\
$\underline{\text { deviate }}$ & 6 & 2 & 4 & 6 & 4 & 3 & 1 & 0 & 1 & 0 & 2.7 \\
\hline
\end{tabular}

Decision maker expected alignment. It is important to note that from a game theoretic perspective the decision maker's uncertainty consisted of two components: uncertainty about the underlying situation and uncertainty about advisor behavior in a given situation. It is not clear to what extent decision makers consciously made such a distinction for their evaluation of the situation; in fact only $53 \%$ stated in the questionnaire that they had thought about how their gains related to the gains of their counterpart. ${ }^{7}$ And yet, their guesses about what alignment was more likely to prevail should be an indicator of whether the context affected their perception of the uncertain situation. In the elicitation phase, decision makers were asked to indicate on a scale from 0 to 9 how well the following statements fit their expectations of the situation.

(0) "The option that gave the highest gain to the advisor was not the option that gave the highest gain to me."

\footnotetext{
${ }^{7}$ In contrast, when asked whether they had thought about how likely it was that their counterpart had told them the truth, $81 \%$ of all decision-makers gave a positive reply.
} 
(9) "The option that gave the highest gain to the advisor was also the option that gave the highest gain to me."

Hence, the statement linked to 0 meant that the decision maker was sure to face a situation of nonaligned interests; the one linked to 9 meant that the decision maker was sure to face a situation of aligned interests.

Whereas the distribution of statements covered the whole range of expectations, the mean was 3.8 in COMP and 5.4 in COOP (Mann-Whitney rank test: $\mathrm{p}<.01$ ). This significant difference in the guesses is striking and it suggests that the context indeed influenced decision makers' perception. In the competitive environment they were more likely to perceive the communication game as a situation of conflict.

Decision makers' verbal explanations. ${ }^{8}$ In the post-questionnaire, decision makers were asked to explain their decision in the communication game. Decision makers were classified according to their actions in the game: follower or deviator. Their explanations were then sorted into categories. Two colleagues volunteered as independent judges. The categories were:

Naïve: The decision maker gave an explanation which describes that he or she simply "believed" / "trusted” / "followed” /... or "disbelieved” / "distrusted” / "deviated” /....

Positive alignment: The decision maker explained the action by stating explicitly that he or she expected the payoff-alignment to be positive.

Negative alignment: The decision maker explained the action by stating explicitly that he or she expected the payoff-alignment to be negative.

Random: The decision maker stated that he or she chose randomly, i.e., independently of the message.

No classification: The judge could not make sense of the explanation.

For followers, one additional category was included:

\footnotetext{
${ }^{8}$ Only decision makers' explanations will be analyzed in detail to receive further insights into the nature of the observed treatment effect. Advisors explanations reflected the aforementioned multiplicity of motivations behind the decision to tell the truth or to lie.
} 
Strategic: The decision maker stated explicitly that he or she followed the advice because he or she thought that the advisor would be strategic in telling the truth, i.e. expecting him or her to deviate.

Observations were counted for a particular category when both judges coincided. When their judgments differed, the observation was entered in the column "judges do not coincide". The results are shown in Table 5.

Table 5 -- Classifications based on actions and verbal explanations

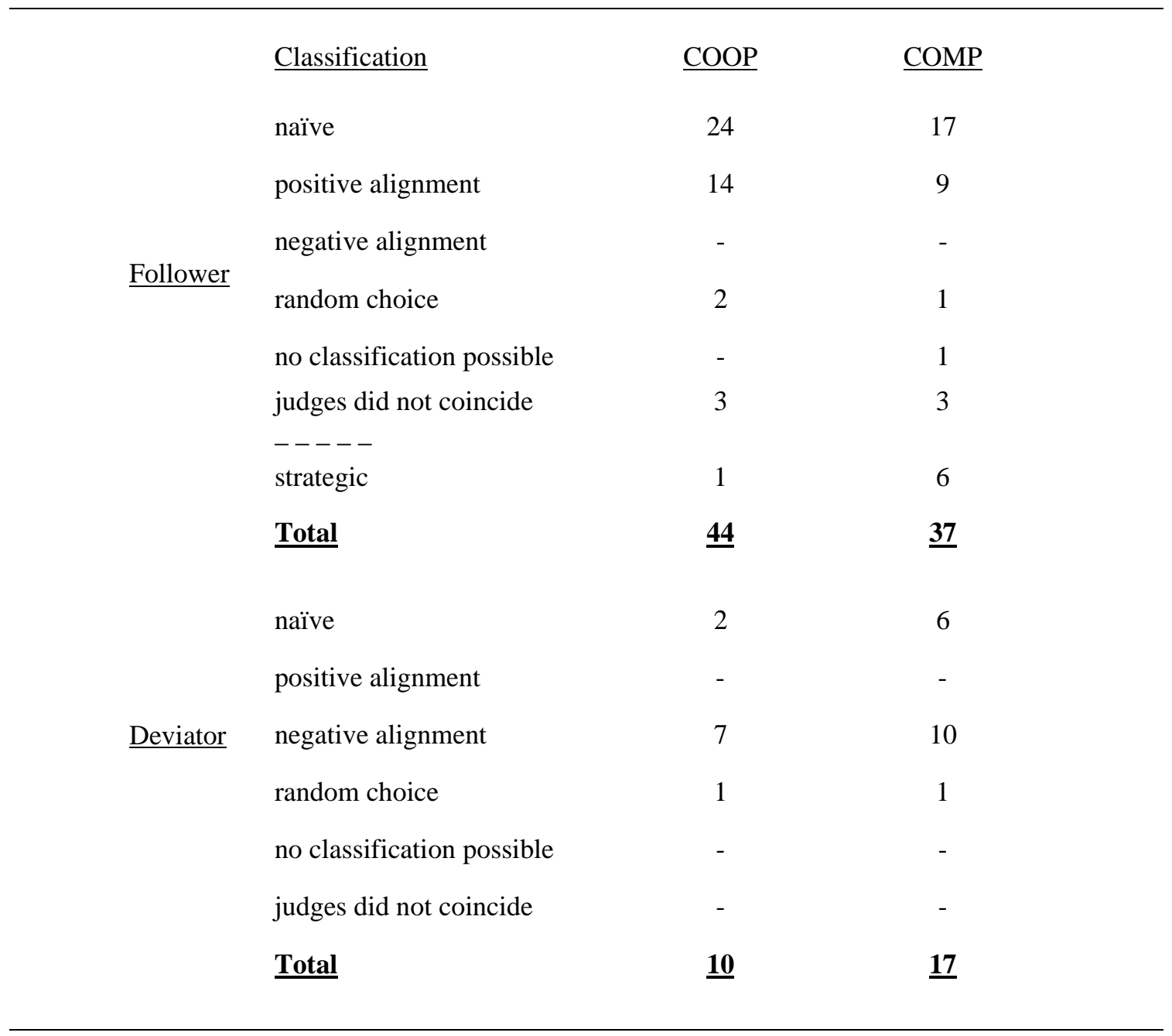

49 of 108 decision-makers (45\%) gave a naïve answer that did not reveal any deeper reasoning behind their choice. The comparison of frequencies of naïve trusters (24 in COOP vs. 17 in COMP) and of naïve deviators (2 in COOP vs. 6 in COMP) are in accordance with the treatment effect. 
40 decision-makers (37\%) referred to the incentive alignment. Again, the frequencies of "positive alignment" (14 in COOP vs. 9 in COMP) and of "negative alignment” (7 in COOP and 10 in COMP) point in the direction of the treatment effect.

An additional insight gained from this analysis was that some decision makers followed strategically due to second-level reasoning. Recall that the payoff structure in the game was selected to rule out strategic truth telling by advisors. However, the uninformed decision maker may have had different expectations. Multi-level reasoning has been reported for many economic games (Stahl and Wilson, 1994; Nagel, 1995; Camerer et al., 2004). It is important to recognize that in the present game, this way of reasoning implied, first, a belief in a negative alignment, and second, a belief in a strategic, self-interested advisor. Consequently, for these decision makers the choice to follow reflected considerations that were contrary to the rest of the followers. In fact, it showed distrust rather than trust, and revealed a weakness of "following” as a behavioral measure of trust in experiment $2 .{ }^{9}$ While strategic following was only a minority phenomenon (7 of 108 decision-makers), it is striking that six of seven cases were in the COMP treatment. As a result, the difference in following understated the effect of the competitive context on trust. With a modified measure of trust as "following not strategically”, the 1-tailed Fisher Exact test clearly rejects independence with respect to the treatments $(\mathrm{p}=.01)^{10}$

\section{Discussion}

\section{The effect of a competitive context on trust in communication}

Results from both versions of the communication game showed that when the interaction took place in a competitive context fewer decision-makers trusted a given advice compared to an equivalent situation which occurred in a cooperative context. This finding may have important practical implications. In Rotter's (1967) words, "one of the most salient factors in the effectiveness of our present complex social organization is the willingness of one or more individuals in a social unit to trust others.” In the same spirit, La Porta et al (1997) have shown that a lack of trust has a negative impact on cooperation and overall efficiency. For instance, the present finding implies that firms

\footnotetext{
${ }^{9}$ It is unlikely that such a reasoning was applied in experiment 1 with 6 options.

${ }^{10}$ Similarly, Sutter (2006) proposes to include strategic truth telling by advisors in the two-option version of the Communication Game into the category of "deception”.
} 
should be careful when evaluating the consequences of different corporate reward system. Overly competitive schemes may have the side effect of decreasing trust in communication among employees. Conversely, a more cooperative environment may increase trust.

Although I agree with Levitt and List (2006) that laboratory experiments are generally better suited for qualitative rather than precise quantitative predictions, the difference in effect size between the two experiments seems intriguing. According to Cohen's (1988) classification, the size of the treatment effect under full uncertainty in experiment 1 is "large" (Cohen's $d=.79$ ), while the treatment effect under partial uncertainty in experiment 2 is "medium" $(\mathrm{d}=.27$ for trust measured as "following"; $\mathrm{d}=.48$ for trust measured as "following not strategically"). Why did the contextual variation affect decision makers more when they were fully uncertain about consequences of their choice compared to a situation with fewer options and when some numerical information was provided? Recall that the additional information in experiment 2 did not reveal the incentive alignment. From a rational choice perspective, while there should have been no effect of the context (i.e., the objectively unrelated first five interactions) in the first place, there was also no reason why the effect should have differed between experiments 1 and 2. Similar to the present results, Vlaev and Chater (2006) find effects of the nature of preceding games on later interactions, which they refer to as "game relativity".

This paper favours an explanation of the results based on psychological theories of automatic vs. controlled information processing (e.g., Schneider and Shiffrin, 1977), and on experimental evidence reviewed by Bargh and Chartrand (1999). Bargh and Chartrand emphasize the limited role of conscious thought for judgment and decision making in many domains of human activity. They conclude that "automatic evaluation of the environment is a pervasive continuous activity that individuals do not intend to engage in and of which they are largely unaware (p. 475).” The distinction between automatic and controlled processes has also found increasing attention in recent neuroeconomic studies (e.g., Sanfey et al., 2006; Knoch et al., 2006). Sanfey et al. write that "perhaps the single most important perspective that neuroscience brings is to challenge the core assumption in economics that behavior can be understood in terms of unitary evaluative and decision-making systems (p.111).” In accordance with this insight, context effects in the present experiment may have 
resulted to a large extent from automatic rather than from controlled evaluation of the environment during parts 1 to 5 . But then, recall that decision makers under full uncertainty in experiment 1 had no additional information apart from the message. In contrast, decision makers in experiment 2 had some numerical information available. Even though this information did not reveal the incentive structure and was therefore objectively irrelevant for the decision whether to follow the advice or not, it provided decision makers with input on which they could base controlled calculations. According to Sanfey et al. (2006) the distinction between controlled and automatic processing is a continuum rather than a qualitative dichotomy. Automatic evaluation may have been less dominant in experiment 2, and context hence affected the decision to a lesser degree than in experiment 1 . The present data are tentative evidence for this explanation. In any case, the result that uncertainty fosters the sensitivity of behavior to contextual cues is interesting and may be addressed in future research.

\section{Subjective beliefs as a basis for theory}

Bayesian Nash equilibrium analysis (Harsanyi, 1967) is certainly the most prominent theoretical solution concept for interactive decisions under uncertainty. Yet, theorists have long recognized that it faces difficulties for complex games, and that predictions often do not match observed behavior (cf., Kadane and Larkey, 1982; Kalai and Lehrer, 1995; Aumann and Dreze, 2005). In the present game, Bayesian Nash analysis predicts uniform beliefs across individuals and insensitivity to the context, whereas the data were characterized by substantial heterogeneity, both for beliefs and actions, and by sensitivity to the context. Moreover, the analysis of beliefs about the counterpart's behavior in experiment 2 revealed that actions and beliefs were correlated. Hence, a modeling approach based on subjective beliefs seems promising to describe the data. In this section the paper compares observed behavior with predictions from expected payoff maximization based on subjective beliefs. The Appendix reconciles these calculations with Subjective Equilibrium Analysis by Kalai and Lehrer (1995).

The graph in Figure 1 depicts advisors' expected gains from each message as a function of their belief of how likely it is that decision makers follow the advice. It is profitable to choose message A if the probability of following is less than $1 / 3$ and to choose message $B$ it is higher than $1 / 3$. If the probability exactly equals $1 / 3$, then payoff-maximizing advisors should be indifferent between all 
messages; in particular this is the only belief for which the truthful message $\mathrm{C}$ is a gains-maximizing action.

Figure 1 -- Distribution of the frequencies of advisor belief-action pairs (see Table 3) and advisors' expected gains as a function of their belief. Belief-action pairs in bold are the payoff-maximizing choices given the subjective belief.

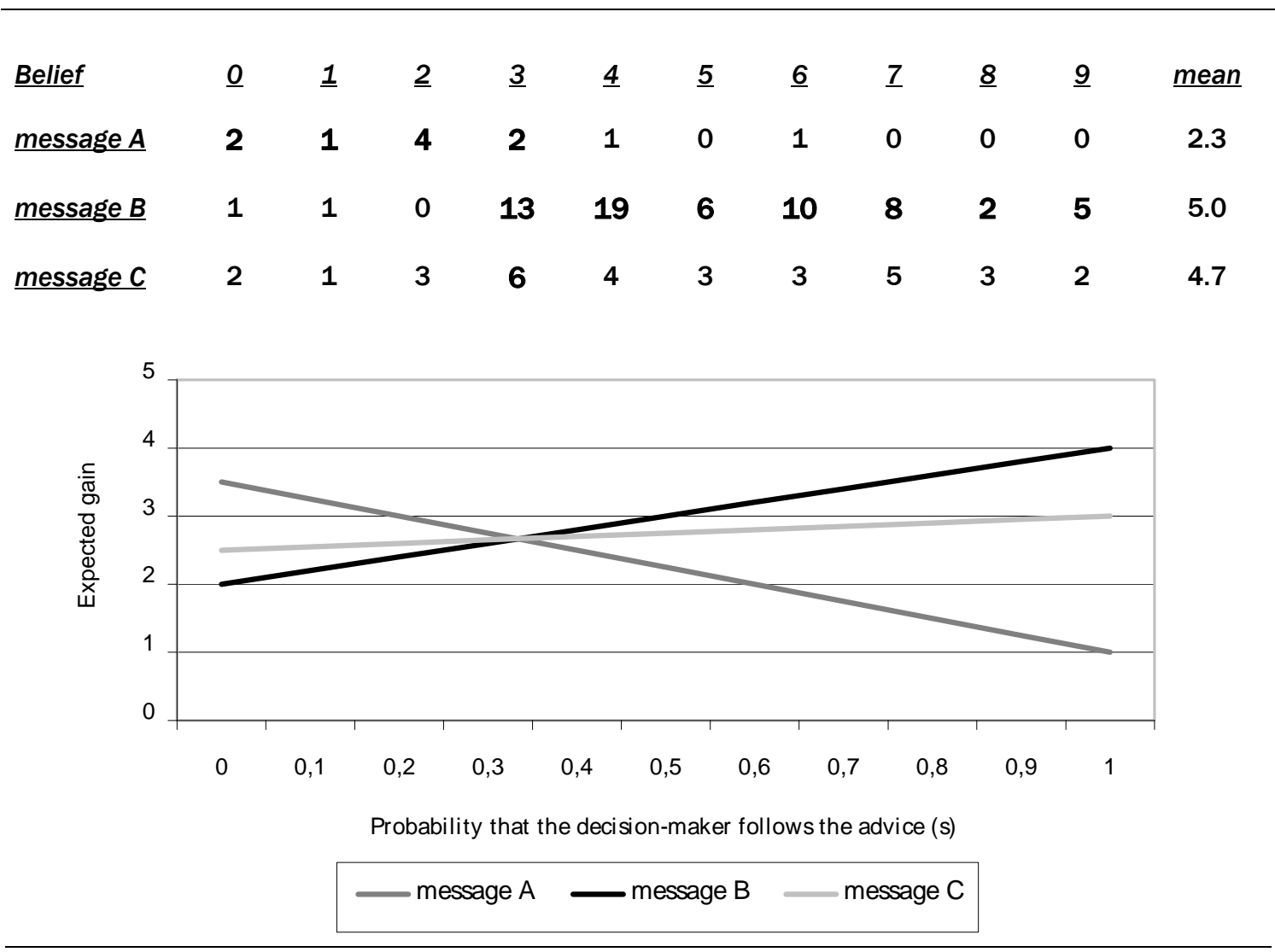

The graph in Figure 2 shows decision makers' expected gains from following or deviating as a function of their belief of how likely it is that advisers tell the truth in the message. It is profitable to deviate if the probability is less than $1 / 3$; following is more profitable if it is more than $1 / 3$. For a probability that exactly equals $1 / 3$, payoff-maximizing decision makers should be indifferent between following and deviating.

The tables above the graphs in Figures 1 and 2 are the same as Tables 3 and 4 in the results section, but now they indicate in bold those action-belief combinations which correspond with the predictions from payoff-maximization given subjective beliefs. For those advisors who chose to lie by sending messages A or B, the calculation predicts behavior correctly in 72 out of 76 cases (95\%). The 
majority of truth-tellers (those with belief $\neq 3$ ) were not in line with the prediction. Decision maker behavior was largely in line with the model (88\%). Many of the 13 decision makers who did not behave in line deviated with a belief of little above the critical value of 1/3.

Figure 2 - Distribution of the frequencies of decision-maker belief-action pairs (see Table 4) and advisors' expected gains as a function of their belief. Belief-action pairs in bold are the payoff-maximizing choices given the subjective belief.

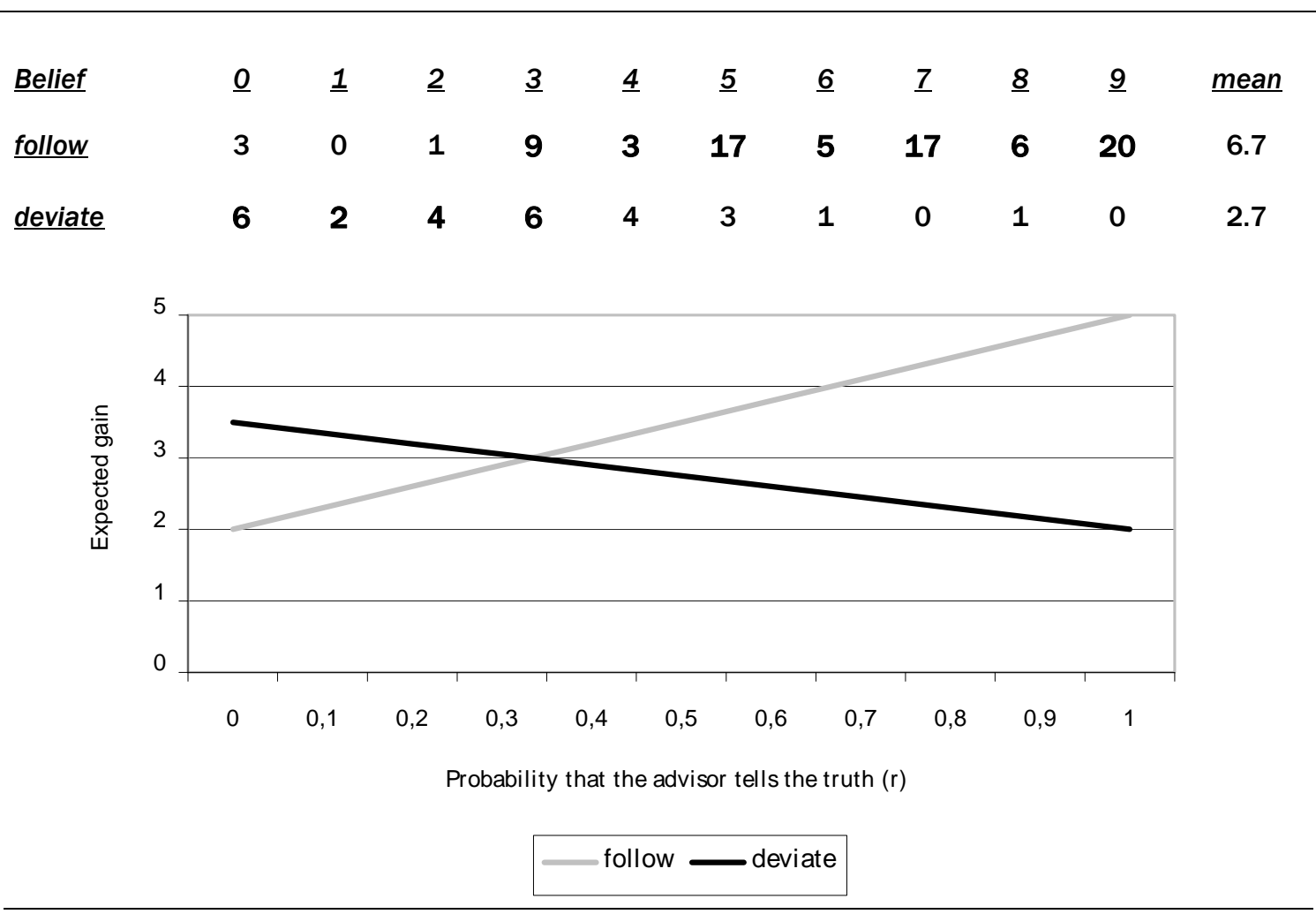

The model describes behavior well for this population, with the exception of truth-telling advisors. Note that advisors had to trade off between maximizing their own gains by lying and maximizing their counterpart's gains by telling the truth. This constituted an ethical dilemma. Evidently, a descriptively adequate model should also allow for non-self-interested motivations. As said, the extent to which truth telling in this situation reflects altruism, an aversion towards the act of lying, or other motivations is the topic of other research on deception. Hurkens and Kartik (2006) show that what looks like behavior motivated by an aversion towards lying may be explained also by (social) preferences over outcomes. For modeling purposes, several authors have suggested a behavioral type approach in which 
certain types of players act upon preferences or action tendencies that deviate from self-interest and economic rationality (Crawford, 2003; Chen, 2004; Cai and Wang, 2006).

\section{Conclusion}

The importance of context effects for interactive decision making is increasingly recognized among economists. This paper presents results from two experiments in which behavior and perceptions of decision makers were altered due to the characteristics of objectively unrelated prior interaction. More explicitly, decision makers trusted significantly less often in the recommendations from a better informed advisor when the context was competitive as opposed to cooperative. While this result is interesting in itself, it may have important practical implications. Many firms rely on competition to motivate their employees. Since it is a well-established insight that trust is important for smooth functioning and for efficiency within organizations, the present finding may be evidence of negative side effects of an overly competitive work environment.

Moreover, the experiments showed that decision makers' sensitivity to contextual effects was strongest when they were fully uncertain about consequences compared to the case when they had some objectively irrelevant information. The paper relates this finding to psychological and neuroscientific work on automatic vs. controlled information processing. It is argued that information processing of contextual cues is to a large extent automatic, and that the impact of such automatic processing on actual decisions may be more dominant when less explicit information is available.

Last, the data of the present study support modeling approaches based on subjective beliefs. In particular, Subjective Equilibrium Analysis (Kalai and Lehrer, 1995) is suggested as a promising tool to maintain some consistency requirements for descriptive and predictive purposes in interactive decisions with uncertainty. 


\section{Bibliography}

Akerlof, G., 1970. The market for „lemons“: Quality uncertainty and the market mechanism. Quarterly Journal of Economics 84 (3), 488-500.

Aumann, R., Dreze, J., 2005. When all is said and done, how should you play and what should you expect?. Discussion paper 2005 - 21. Université Catholique de Louvain.

Bargh, J., Chartrand, T., 1999. The Unbearable Automaticity of Being. American Psychologist 54 (7), 462-479.

Berg, J., Dickhaut, J., McCabe, K., 1995. Trust, Reciprocity, and Social History. Games and Economic Behavior 10, pp. 122-142.

Blume, A., DeJong, D., Kim Y., Sprinkle, G., 1998. Experimental Evidence on the Evolution of Meaning of Messages in Sender-Receiver Games. American Economic Review 88 (5), 1323-1340.

Blume, A., DeJong, D., Kim Y., Sprinkle, G., 2001. Evolution of Communication with Partial Common Interest. Games and Economic Behavior 37, 79-120.

Brandts, J., Riedl, A., van Winden, F., 2005. Competition and well-being. IZA Discussion Paper Series, 1769. Bonn.

Cai, H., Wang, J., 2006. Overcommunication in strategic information transmission games. Games and Economic Behavior 56, 7-36.

Camerer, C., Ho, T.-H., Chong, J.-K., 2004. A Cognitive Hierarchy Model of Games. Quarterly Journal of Economics 119 (3), 861-898.

Camerer, C., Loewenstein, G., Weber, M., 1989. The curse of knowledge in economic settings: An experimental analysis. Journal of Political Economy 97 (5), 1232-1254.

Charness, G., Dufwenberg, M., 2005. Deception: The role of guilt. Working paper. University of Arizona, Tucson.

Chen, Y., 2004. Perturbed Communication Games with Honest Senders and Naïve Receivers. Unpublished. 
Cohen, J., 1988. Statistical power analysis for the behavioral sciences (2nd ed.). Hillsdale, NJ: Lawrence Earlbaum Associates.

Dickhaut, J., McCabe, K., Mukherji, A., 1995. An experimental study of strategic information transmission. Economic Theory 6 (3), 389-403.

Crawford, V., 1998. A Survey of Experiments on Communication via Cheap Talk. Journal of Economic Theory 78, 286-298.

Crawford, V., 2003. Lying for Strategic Advantage: Rational and Boundedly Rational Misrepresentation of Intentions. American Economic Review 93 (1), 133-149.

Crawford, V., Sobel, J., 1982. Strategic Information Transmission. Econometrica 50 (6), 1431-1451.

Farrell, J., Rabin M., 1996. Cheap talk. Journal of Economic Perspectives 10 (3), 103-118.

Fischbacher, U., 2007. z-Tree: Zurich Toolbox for Ready-made Economic experiments. Experimental Economics 10(2), 171-178.

Ford, R., Richardson W., 1994. Ethical decision making: A review of the empirical literature. Journal of Business Ethics 13, 205-221.

Fukuyama, F., 1995. Trust: The Social Virtues and the Creation of Prosperity. The Free Press, New York.

Greiner, B., 2003. An Online Recruitment System for Economic Experiments. In: Kurt Kremer, Volker Macho (Eds.): Forschung und wissenschaftliches Rechnen 2003. GWDG Bericht 63, Göttingen : Ges. für Wiss. Datenverarbeitung, 79-93, 2004.

Gneezy, U., 2005. Deception: The role of consequences. American Economic Review 95 (1), 384-394.

Harsanyi, J., 1967. Games of Incomplete Information Played by Bayesian Players, Part I. Management Science 14, 159-182.

Hegarty, W., Sims, H., 1978. Some determinants of unethical decision behavior: An experiment. Journal of Applied Psychology 63 (4), 451-457. 
Hogarth, R., 2005. The challenge of representative design in psychology and economics. Journal of Economic Methodology 12 (2), 253-263.

Hurkens, S., Kartik, N., 2006. (When) Would I lie to you? Comment on "Deception: The role of consequences”. Working paper. University of California San Diego.

Kadane, J., Larkey, P., 1982. Subjective probability and the theory of games. Management Science 28 (2), 113-120.

Kalai, E., Lehrer, E., 1995. Subjective Games and Equilibria. Games and Economic Behavior 8 (1), 123-163.

Knack, S., Keefer, P., 1997. Does Social Capital Have an Economic Payoff? A Cross-Country Investigation. Quarterly Journal of Economics 112 (4), 1251-1288.

Knack, S., 2001. Trust, Associational Life and Economic Performance. In: The Contribution of Human and Social Capital to Sustained Economic Growth and Well Being. International Symposium Report. HRDC-OECD.

Knoch, D., Pascual-Leone, A., Meyer, K., Treyer, V., Fehr, E., 2006. Diminishing Reciprocal Fairness by Disrupting the Right Prefrontal Cortex. Science 314, 829-832.

Laplace, P., 1824. Essai Philosophique sur les Probabilités. Dover (English translation).

La Porta, R., Lopez-de-Silanes, F., Shleifer, A., Vishny, R., 1997. Trust in Large Organizations. American Economic Review Papers and Proceedings 87 (2), 333-338.

Lawler, E., 2000. Rewarding Excellence: Pay Strategies for the New Economy. Jossey-Bas, San Francisco.

Levitt, S., List, J., 2006. What do Laboratory Experiments tell us about the real world?. Working Paper. University of Chicago.

McKnight, D., Chervany, N., 2001. Trust and Distrust Definitions: One bite at a time. In: Falcone, R., Singh, M., Tan, Y.-H. (Eds.), Trust in Cyber-societies : Integrating the Human and Artificial Perspectives. Springer Verlag, Berlin, pp. 27-54. 
Nagel, R., 1995. Unraveling in Guessing Games: An experimental Study. American Economic Review 85, 1313-1326.

Ross, W., Robertson, D., 2000. Lying: The impact of the decision context. Business Ethics Quarterly 10 (2), 409-440.

Rotter, J., 1971. Generalized expectancies for interpersonal trust. American Psychologist 26, 443-452.

Rotter, J., 1980. Interpersonal trust, trustworthiness and gullibility. American Psychologist 35 (1), 1-7.

Sanfey, A., Loewenstein, G., McClure, S., Cohen, J., 2006. Neuroeconomics: cross-currents in research on decision-making. Trends in Cognitive Sciences 10 (3), 108-116.

Schneider, W., Shiffrin, R., 1977. Controlled and automatic human information processing: I. Detection, search, and attention. Psychological Review 84, 1-66.

Schwieren, C., Brandts, J., Weichselbaumer, D., 2006. The effect of competition on behavior in Trust Games. Paper presented at IAREP-SABE 2006 conference.

Stahl, D., Wilson, P., 1994. Experimental evidence of players' models of other players. Journal of Economic Behavior and Organization 25 (3), 309-327.

Sutter, M., 2006. Deception: The role of expectations. A comment on Gneezy (2005). Working paper. University of Cologne.

Van Knippenberg, B., Van Knippenberg, D., Wilke, H., 2001. Power Use in Cooperative and Competitive Settings. Basic and Applied Social Psychology 23 (4), 291-300.

Vlaev, I., Chater, N., 2006. Game Relativity: How Context Influences Strategic Decision Making. Journal of Experimental Psychology 32 (1), 131-149.

Yamagishi, T., Yamagishi, M., 1994. Trust and Commitment in the United States and Japan. Motivation and Emotion 18 (2), 129-166. 


\section{Appendix 1 -- Subjective Equilibrium Analysis (SEA)}

Subjective Equilibrium Analysis (Kalai and Lehrer, 1995) - henceforth SEA - aggregates all uncertainty a player may have and describes it by an "environment response function". This function specifies a probability distribution over all outcomes that may result from a particular action. A player is subjectively rational if his action is optimal given his subjective environment response function. Importantly, the model explicitly allows for individually subjective assessments of the probabilities. They are neither assumed to be "correct” nor to coincide with those of other players.

Let the advisor's action space be the possible messages $a_{\mathrm{adv}} \in A_{\mathrm{adv}}=\{\mathrm{A}, \mathrm{B}, \mathrm{C}\}$ and the decision maker's action space the possible choices $a_{\mathrm{dm}} \in A_{\mathrm{dm}}=\{\mathrm{A}, \mathrm{B}, \mathrm{C}\}$. Denote $o^{*} \in O^{*}=\left\{\mathrm{A}^{*}, \mathrm{~B}^{*}, \mathrm{C}^{*}\right\}$ as the states in which $A, B, C$, respectively, is the option with the highest gain ( $€ 5$ ) for the decision maker. Clearly, only the advisor knows that in fact $\mathrm{C}^{*}$ is the true state, i.e., the probability $P_{\mathrm{adv}}\left(\mathrm{C}^{*}\right)=$ 1 , and $P_{\text {adv }}\left(\mathrm{A}^{*}\right)=P_{\mathrm{adv}}\left(\mathrm{B}^{*}\right)=0$. The Principle of Insufficient Reasoning (PIR) (Laplace, 1824) suggests that the decision maker attributes the same probability to all $o^{*} \in O^{*}$, i.e., $P_{\mathrm{dm}}\left(\mathrm{A}^{*}\right)=P_{\mathrm{dm}}\left(\mathrm{B}^{*}\right)=P_{\mathrm{dm}}$ $\left(C^{*}\right)=1 / 3$. Consequently, the following assumption is made:

Indifference: Ex ante, the decision maker has no preference for a particular option over the others, and the advisor knows this.

Under this assumption, the decision maker's choice is between the option that is indicated in the advice (follow) or selecting randomly one of the remaining two options (deviate). Hence, one can specify the advisor's environment response function based on the belief about the probability with which the decision maker follows the advice. For the decision maker, an environment response function can be based on his subjective belief about the probability that the message is truthful.

Advisors. Let $P_{\mathrm{adv}}\left(a_{\mathrm{dm}} / a_{\mathrm{adv}}\right)$ be the probability that the advisor attributes to the decision maker's choice of $a_{\mathrm{dm}}$ given message $a_{\mathrm{adv}}$. Let $s$ be advisor's subjective belief of the probability that the decision maker follows the advice. In accordance with Indifference, $s$ is independent of the message, so that

$$
P_{\text {adv }}(\mathrm{A} / \mathrm{A})=P_{\mathrm{adv}}(\mathrm{B} / \mathrm{B})=P_{\mathrm{adv}}(\mathrm{C} / \mathrm{C})=s .
$$


Indifference also ensures that the advisor expects the decision maker to deviate to the two remaining options with equal probability. Since $\sum_{a_{d m} \in A_{d m}} P_{a d v}\left(a_{d m} / a_{a d v}\right)=1$ must hold for all $a_{\mathrm{adv}}$,

$$
\begin{aligned}
& P_{\mathrm{adv}}(\mathrm{B} / \mathrm{A})=P_{\mathrm{adv}}(\mathrm{C} / \mathrm{A}) \\
= & P_{\mathrm{adv}}(\mathrm{A} / \mathrm{B})=P_{\mathrm{adv}}(\mathrm{C} / \mathrm{B}) \\
= & P_{\mathrm{adv}}(\mathrm{A} / \mathrm{C})=P_{\mathrm{adv}}(\mathrm{B} / \mathrm{C}) \\
= & \frac{(1-s)}{2}
\end{aligned}
$$

This specifies the advisor's environment response function. Expected gains $\left(E \pi_{a d v}\right)$ from messages A, B and C are

$$
\begin{aligned}
& E \pi_{a d v}[A]=s+4 \frac{(1-s)}{2}+3 \frac{(1-s)}{2}=3.5-2.5 s \\
& E \pi_{a d v}[B]=4 s+1 \frac{(1-s)}{2}+3 \frac{(1-s)}{2}=2+2 s \\
& E \pi_{a d v}[C]=3 s+1 \frac{(1-s)}{2}+4 \frac{(1-s)}{2}=2.5+.5 s
\end{aligned}
$$

Figure 1 shows graphically $E \pi_{a d v}$ for each message $a_{\text {adv }}$ as a function of $s$. For an advisor who maximizes expected gains, it is profitable to choose message A if $s<1 / 3$ and to choose message B if $s$ $>1 / 3$. For $s=1 / 3$ the advisor is indifferent between all messages, in particular it is the only belief for which the truthful message $\mathrm{C}$ is a gains-maximizing response.

Decision makers. Let $P_{\mathrm{dm}}\left(O^{*} / a_{\mathrm{adv}}\right)$ be the probability that the decision maker attributes to $o^{*}$ given that she received message $a_{\mathrm{adv}}$. Let $r$ be the decision maker's subjective belief of the probability that the received message is truthful. PIR (Principle of Insufficient Reasoning) ensures that $r$ is the same for all received messages; i.e.

$$
P_{\mathrm{dm}}(\mathrm{A} * / \mathrm{A})=P_{\mathrm{dm}}(\mathrm{B} * / \mathrm{B})=P_{\mathrm{dm}}(\mathrm{C} * / \mathrm{C})=r .
$$

PIR also ensures that given he received a message $a_{\mathrm{A}}$, the decision maker attributes equal probability to the two remaining options being the ones with the highest payoffs. Under the condition

$$
\text { that } \begin{aligned}
& P_{\mathrm{dm}}\left(\mathrm{A} * / a_{\mathrm{adv}}\right)+P_{\mathrm{dm}}\left(\mathrm{B} * / a_{\mathrm{adv}}\right)+P_{\mathrm{dm}}\left(\mathrm{C} * / a_{\mathrm{adv}}\right)=1 \text { for all } a_{\mathrm{adv}}, \\
& P_{\mathrm{dm}}\left(\mathrm{B}^{*} / \mathrm{A}\right)=P_{\mathrm{dm}}(\mathrm{C} * / \mathrm{A}) \\
= & P_{\mathrm{dm}}(\mathrm{A} * / \mathrm{B})=P_{\mathrm{dm}}(\mathrm{C} * / \mathrm{B}) \\
= & P_{\mathrm{dm}}(\mathrm{A} * / \mathrm{C})=P_{\mathrm{dm}}(\mathrm{B} * / \mathrm{C})
\end{aligned}
$$


$=\frac{(1-r)}{2}$.

This specifies the decision maker's environment response function. The following expected gains $\left(E \pi_{d m}\right)$ result:

$$
\begin{aligned}
& E \pi_{d m}[\text { follow }]=5 r+\frac{(1-r)}{2}+3 \frac{(1-r)}{2}=2+3 r \\
& E \pi_{d m}[\text { deviate }]=\frac{r}{2} \times(1+3)+\frac{1}{2}\left[\frac{(1-r)}{2} \times(1+5)+\frac{(1-r)}{2}(3+5)\right]=3.5-1.5 r
\end{aligned}
$$

Figure 2 shows the decision maker's expected monetary gains $E \pi_{d m}$ from following or deviating as a function of $r$. It is profitable to follow if $r>1 / 3$ and to choose deviate if $r<1 / 3$. For $r=1 / 3$ the decision maker is indifferent between following and deviating. 


\section{Appendix 2 - Experimental instructions}

\section{Basic instructions}

Thanks for participating in this experiment, which is part of a research project. The money that you can gain depends on your results in the exercises and on your decisions, and the results and decisions of the other participants. From now on until the end of the experiment you are not allowed to talk. Thank you!

The experiment consists in several consecutive parts. At the beginning of each part of the experiment you will receive detailed instructions about what you have to do and how zou can gain money. Please read the instructions carefully. Press "OK" to continue only when you have fully understood the instructions. If you have any questions, raise your hand and one of the instructors will answer you. Please do not ask aloud!

In each part of the experiment you will be randomly assigned another participant. It will be someone different in each part, but you will never know who it is.

In each part, you and the other participant will encounter either an exercise in which your results will be rewarded, or an interaction, in which you have to make a decision. As said, you will receive further instructions at the beginning of each part.

After each part, you will be told how much you have gained, and how much money you have accumulated in total.

No one will know your results or your decisions in the experiment!

If you have a question, please ask the instructor at any time!

Thank you for your participation!

\section{Instructions for first exercise}

\section{Part 1}

This part consists of an exercise for you and another participant [COMP: This part consists in an exercise in which you compete against another participant]. Remember that the participant you get assigned to will change in the following parts.

The exercise consists in solving easy calculations. You have to solve 30 calculation exercises. Fill in the correct solution behind each one of them. You have 3 minutes to solve as many calculations as possible.

Example: A calculation could be $7+3=[10]$.

To determine the money that you and the other participant will receive, the numbers of correct solutions of each one of you are summed up. Then this sum is multiplied by 0.05 Euros. This will be the money accumulated for your gains in this part of the experiment.

Example: You have 25 correct solutions and the other has 20.

In this case you would have accumulated $(25+20) \times 0.05 €=2.25 €$.

You and the other participant each receive half of the accumulated gains.

Example: You receive both $1 / 2 \times 2.25 €=1.13 €$.

[COMP: If you have more correct solutions than the other participant, then you win and receive two thirds of the accumulated money. If you have fewer correct solutions than the other, then you loose and receive one third of the accumulated money. If you have both the same number of correct solutions, then you both receive half of the money.

\section{Example:}

You win and receive $2 / 3 \times 2.25 €=1.50 €$; the other looses and receives $1 / 3 \times 2.25 €=0.75 €$.]

Please press "OK" when you are ready. The calculations will appear when you have pressed "OK" and the time (3 minutes) will begin to count. 


\section{Instructions for the communication game}

\section{Advisor}

Part 6

This part consists in an interaction between you and the other participant. You have to take a decision. In this part you and the other participant have three possible options with different gains.

$\begin{array}{lll}\text { Option } & \text { for you } & \text { for the other } \\ \text { A: } & 1 € & 1 € \\ \text { B: } & 4 € & 3 € \\ \text { C: } & 3 € & 5 €\end{array}$

You know these payments from the options while the other participant only knows that there are three options A, $\mathrm{B}$, and $\mathrm{C}$, and that with one of the options she gains 1 , with another 3 , and with another 5 Euros. SHE DOES NOT KNOW WHICH OF THE GAINS 1, 3, 5 BELONGS TO WHICH OPTION AND SHE DOES NOT KNOW ANYTHING ABOUT THE GAINS FOR YOU!

This means that the other knows the following:

\begin{tabular}{lll}
\multicolumn{2}{l}{ Option for you } & for her \\
A: & $?$ & 1,3 o $€$ \\
B: & $?$ & $1,305 €$ \\
C: & $?$ & 1,3 o $5 €$
\end{tabular}

The other participant has to choose one of the options! To make her decision, the only additional information that she has will be a message that you send her before she decides.

Your possible messages are:

Message A: "With option A you receive more money than with the other options".

Message B: "With option B you receive more money than with the other options".

Message C: "With option C you receive more money than with the other options".

The other participant will receive your message and then has to choose one of the three options. To repeat, the choice of the other determines the gains in this part. However, she will never know which gains belong to the options that were not chosen and she will never know the value of the gains for you.

\section{Decision maker}

Part 6

This part consists in an interaction between you and the other participant. You have to take a decision. In this part you and the other participant have three possible options with different gains. YOU HAVE TO MAKE A CHOICE BETWEEN THE THREE OPTIONS. OPTION A, B, or C. That means that the gains in this part depend on your choice. However, you only know the following:

ONE OF THE OPTIONS GIVES YOU A GAIN OF $1 €$, ANOTHER A GAIN OF $3 €$, ANOTHER OF $5 €$ (this means that you do not know the order).

The other participant knows the gains from each option for both of you. THIS MEANS THAT THE OTHER PARTICIPANT KNOWS EXACTLY WHICH GAINS FOR YOU (1, 3, and 5) BELONG TO WHICH

OPTION!!! The only additional information that you have is a message that the other participant sends you.

The possible messages are:

Message A: "With option A you receive more money than with the other options".

Message B: "With option B you receive more money than with the other options".

Message C: "With option $\mathrm{C}$ you receive more money than with the other options".

After receiving the message, you will have to choose between the three options. You will never know which gains belong to the options that you have not chosen. 


\begin{tabular}{|c|c|c|}
\hline Nr. & Author & 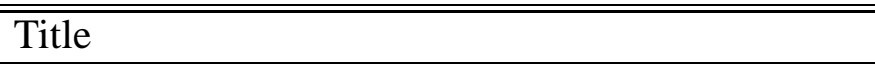 \\
\hline $08-02$ & $\begin{array}{l}\text { Siegfried K. Berninghaus } \\
\text { Karl-Martin Ehrhart } \\
\text { Marion Ott }\end{array}$ & $\begin{array}{l}\text { Myopically Forward-Looking Agents in a Network } \\
\text { Formation Game: Theory and Experimental } \\
\text { Evidence }\end{array}$ \\
\hline $08-01$ & $\begin{array}{l}\text { Sascha Huber } \\
\text { Thomas Gschwend } \\
\text { Michael F. Meffert } \\
\text { Franz Urban Pappi }\end{array}$ & $\begin{array}{l}\text { Erwartungsbildung über den Wahlausgang und ihr } \\
\text { Einfluss auf die Wahlentscheidung }\end{array}$ \\
\hline $07-76$ & $\begin{array}{l}\text { Michael Bremert } \\
\text { Dennis Voeller } \\
\text { Nicole Zein }\end{array}$ & $\begin{array}{l}\text { Interdependencies between Elements of } \\
\text { Governance and Auditing: Evidence from Germany }\end{array}$ \\
\hline $07-75$ & $\begin{array}{l}\text { Jannis Bischof } \\
\text { Jens Wüstemann }\end{array}$ & $\begin{array}{l}\text { How Does Fair Value Measurement under IAS } 39 \\
\text { Affect Disclosure Choices of European Banks? }\end{array}$ \\
\hline $07-74$ & $\begin{array}{l}\text { Markus Glaser } \\
\text { Philipp Schäfers } \\
\text { Martin Weber }\end{array}$ & $\begin{array}{l}\text { Managerial Optimism and Corporate Investment: Is } \\
\text { the CEO Alone Responsible for the Relation? }\end{array}$ \\
\hline $07-73$ & $\begin{array}{l}\text { Jannis Bischof } \\
\text { Michael Ebert }\end{array}$ & $\begin{array}{l}\text { IAS } 39 \text { and Biases in the Risk Perception of } \\
\text { Financial Instruments }\end{array}$ \\
\hline $07-72$ & $\begin{array}{l}\text { Susanne Abele } \\
\text { Garold Stasser }\end{array}$ & $\begin{array}{l}\text { Continuous and Step-level Pay-off Functions in } \\
\text { Public Good Games: A Conceptual Analysis }\end{array}$ \\
\hline $07-71$ & $\begin{array}{l}\text { Julian Rode } \\
\text { Marc Le Menestrel }\end{array}$ & The role of power for distributive fairness \\
\hline $07-70$ & $\begin{array}{l}\text { Markus Glaser } \\
\text { Martin Weber }\end{array}$ & $\begin{array}{l}\text { Why inexperienced investors do not learn: They do } \\
\text { not know their past portfolio performance }\end{array}$ \\
\hline $07-69$ & $\begin{array}{l}\text { Jose Apesteguia } \\
\text { Steffen Huck } \\
\text { Jörg Oechssler } \\
\text { Simon Weidenholzer }\end{array}$ & $\begin{array}{l}\text { Imitation and the Evolution of Walrasian Behavior: } \\
\text { Theoretically Fragile but Behaviorally Robust }\end{array}$ \\
\hline $07-68$ & $\begin{array}{l}\text { Damian S. Damianov } \\
\text { Jörg Oechssler }\end{array}$ & $\begin{array}{l}\text { Uniform vs. Discriminatory Auctions with Variable } \\
\text { Supply - Experimental Evidence }\end{array}$ \\
\hline
\end{tabular}




\begin{tabular}{lll}
\hline \hline Nr. & Author & Title
\end{tabular}

07-67 Dirk Simons

Barbara E. Weißenberger

07-66 Alexander Ludwig

Alexander Zimper

07-65 Alexander Ludwig Alexander Zimper

07-64 Michael F. Meffert

Thomas Gschwend

07-63 Michael F. Meffert

Thomas Gschwend

07-62 Peter Dürsch

Maros Servátka

07-61 Wendelin Schnedler

Radovan Vadovic

07-60 Volker Stocké

07-59 Christopher Koch

Martin Weber

Jens Wüstemann

07-58 Sylvain Béal

07-57 Sylvain Béal

Jacques Durieu

Philippe Solal

07-56 Alen Nosic

Martin Weber
Die Konvergenz von externem und internem

Rechnungswesen ñKritische Faktoren für die

Entwicklung einer partiell integrierten

Rechnungslegung aus theoretischer Sichtñ

Attitude polarization

A Parsimonious Model of Subjective Life

Expectancy

Voting for Coalitions? The Role of Coalition

Preferences and Expectations in Voting Behavior

Polls, Coalition Signals, and Strategic Voting: An

Experimental Investigation of Perceptions and

Effects

Risky Punishment and Reward in the Prisoner

Legitimacy of Control

Strength, Sources, and Temporal Development of Primary Effects of Families' Social Status on Secondary School Choice

Can Auditors Be Independent? - Experimental Evidence

PERCEPTRON VERSUS AUTOMATON\&8727;

Farsighted Coalitional Stability in TU-games

Determinants of Risk Taking Behavior: The role of Risk Attitudes, Risk Perceptions and Beliefs 


\begin{tabular}{|c|c|c|}
\hline Nr. & Author & Title \\
\hline $07-55$ & $\begin{array}{l}\text { Michael F. Meffert } \\
\text { Thomas Gschwend }\end{array}$ & $\begin{array}{l}\text { Strategic Voting under Proportional Representation } \\
\text { and Coalition Governments: A Simulation and } \\
\text { Laboratory Experiment }\end{array}$ \\
\hline $07-54$ & Klaus Fiedler & $\begin{array}{l}\text { Pseudocontingencies - A key paradigm for } \\
\text { understanding adaptive cognition }\end{array}$ \\
\hline $07-53$ & $\begin{array}{l}\text { Florian Kutzner } \\
\text { Peter Freytag } \\
\text { Tobias Vogel } \\
\text { Klaus Fiedler }\end{array}$ & $\begin{array}{l}\text { Base-rate neglect based on base-rates in } \\
\text { experience-based contingency learning }\end{array}$ \\
\hline $07-52$ & $\begin{array}{l}\text { Klaus Fiedler } \\
\text { Yaakov Kareev }\end{array}$ & $\begin{array}{l}\text { Implications and Ramifications of a Sample-Size } \\
\text { Approach to Intuition }\end{array}$ \\
\hline $07-51$ & Klaus Fiedler & $\begin{array}{l}\text { The Ultimate Sampling Dilemma in } \\
\text { Experience-Based Decision Making }\end{array}$ \\
\hline $07-50$ & $\begin{array}{l}\text { Jürgen Eichberger } \\
\text { David Kelsey }\end{array}$ & Ambiguity \\
\hline $07-49$ & Tri Vi Dang & Information Acquisition in Double Auctions \\
\hline $07-48$ & Clemens Kroneberg & $\begin{array}{l}\text { Wertrationalität und das Modell der } \\
\text { Frame-Selektion }\end{array}$ \\
\hline $07-47$ & $\begin{array}{l}\text { Dirk Simons } \\
\text { Nicole Zein }\end{array}$ & Audit market segmentation and audit quality \\
\hline $07-46$ & $\begin{array}{l}\text { Sina Borgsen } \\
\text { Martin Weber }\end{array}$ & $\begin{array}{l}\text { False Consensus and the Role of Ambiguity in } \\
\text { Predictions of Othersí Risky Preferences }\end{array}$ \\
\hline $07-45$ & $\begin{array}{l}\text { Martin Weber } \\
\text { Frank Welfens }\end{array}$ & $\begin{array}{l}\text { An Individual Level Analysis of the Disposition } \\
\text { Effect: Empirical and Experimental Evidence }\end{array}$ \\
\hline $07-44$ & $\begin{array}{l}\text { Martin Weber } \\
\text { Frank Welfens }\end{array}$ & $\begin{array}{l}\text { The Repurchase Behavior of Individual Investors: } \\
\text { An Experimental Investigation }\end{array}$ \\
\hline $07-43$ & $\begin{array}{l}\text { Manel Baucells } \\
\text { Martin Weber } \\
\text { Frank Welfens }\end{array}$ & $\begin{array}{l}\text { Reference Point Formation Over Time: A } \\
\text { Weighting Function Approach }\end{array}$ \\
\hline
\end{tabular}

